\title{
El Pallars en los libros manuscritos y la documentación del Archivo Ducal de Medinaceli*
}

\author{
The Pallars in the manuscript books the documentation of \\ the Ducal Archive of Medinaceli
}

ANTONIO SÁNCHEZ GonZÁLEZ**

RESUMEN

La dilatada historia del dominio feudal de Pallars, en el Pirineo catalán, que arranca en el siglo IX en el seno del Imperio Carolingio, del que pronto se independiza convirtiéndose en condado autónomo, originó un valioso Archivo en poder de sus condes y marqueses, que fue reorganizado y descrito al detalle en el siglo XVII. Esos pergaminos, papeles y libros manuscritos del Pallars (hoy conservados en el Archivo Ducal de Medinaceli) son aquí protagonistas por partida doble: como fuente de primera mano para recrear la evolución histórica pallarense, por un lado, y como integrantes de un archivo condal cuya historia aquí también se desentraña, por otro. Por último, interesantes aspectos del gobierno del dominio catalán y de algunas de las poblaciones que lo componían se describen en varios de sus libros manuscritos.

\section{ABSTRACT}

The extensive history of the feudal dominium of Pallars, in the Catalonia Pyrenees, starts in the $9^{\text {th }}$ century in the Carolingian Empire, from which it will get the independence very soon changing into an autonomous county, originated a valuable Archive owned by his Counts and Marquises was originated. It was reorganized and described in detail in the $17^{\text {th }}$ century. Those scrolls, papers and manuscripts books from Pallars (nowadays maintained in the Ducal Archive of Medinaceli) are protagonists in a double sense, on one hand as first-hand source in order to recreate the Pallars historic evolution; on the other hand as an integral part of a count archive whose history is also unravelled. Finally, some of theirs manuscripts books describe interesting aspects about the Catalonian domain government and about some of its populations.

* Texto abreviado de la conferencia pronunciada en el contexto del Curs d'Historia del Pallars (Sort, abril de 2007).

** Universidad de Huelva. 
PALABRAS CLAVE

Condado de Pallars; Marquesado de Pallars; Archivística nobiliaria; documentación señorial; libros manuscritos; Archivo Condal de Pallars; Archivo Ducal de Medinaceli; Imperio Carolingio (Marca Hispánica); familias

Pallars, Comenge y Mataplana; villas y castillos de Escaló, Sort, Peramea, Salàs, València d'Aneu.

\section{KEY WORDS}

Pallars County; The Marquesses of Pallars; Archivistic of the nobility; Feudal documentation; Manuscripts books; Condal Archive of Pallars; Ducal Archive of Medinaceli; Feudal dominium;

Carolingian Empire (Hispanic or Spanish March); Pallars, Comenge and Mataplana families; Villas and castles from Escaló, Sort, Peramea, Salàs, València d'Aneu.

La rica documentación medieval y moderna del histórico dominio feudal pirenaico de Pallars, en la Alta Cataluña leridana, forma parte desde el siglo XVII del «Archivo de la Casa Ducal de Medinaceli», engrosando por completo la sección «Pallars» y, en menor cuantía, otras secciones facticias y misceláneas del depósito.

Este archivo nobiliario es de una enorme importancia, tanto a nivel cuantitativo como cualitativo. Cuantitativamente porque lo constituye casi un kilómetro lineal de pergaminos y papeles — cantidad nada despreciable para un archivo privado-; pero también cualitativamente tiene una riqueza excepcional porque los numerosos fondos de las distintas Casas nobiliarias que integra mantienen unas series documentales muy completas y homogéneas, con el valor añadido de que la documentación procede prácticamente de todas las comunidades y territorios españoles. El estudio de toda esta documentación permite así que se pueda profundizar de una manera muy exhaustiva y globalizada en el fenómeno del régimen señorial peninsular consultando un solo archivo. Las series, como decimos, se conservan muy completas, y esto a pesar de que la documentación ha pasado a lo largo de los siglos por diferentes vicisitudes y ajetreos, como detallo en uno de mis libros, el titulado «Documentación de la Casa Ducal de Medinaceli: El Archivo General de los duques de Segorbe y Cardona", publicado por el Ministerio de Cultura en 1990. En el caso de los fondos del Pallars la documentación sufrió a lo largo del tiempo algún mal trato pero, en líneas generales, el Archivo se conserva muy bien, y a nivel de instalación se encuentra hoy perfectamente acondicionado.

Este Archivo Ducal estuvo bajo mi dirección entre 1984 y 2000, años en los que realicé una sustancial mejora orgánica de los ricos y variados fondos documentales que integran el depósito. Ese trabajo práctico tuvo además una plasmación teórica en un amplio estudio, que constituyó en su día nuestra tesis doctoral bajo el título «Linajes y estados de la Casa de Medinaceli. Estructura de su memoria archivística» (Universidad de Sevilla, 1989). En esta tesis apliqué unos criterios de contenido - con una estructura en tres partes diferenciadas- que son los mismos que retomo aquí para explicar el caso concreto del Archivo de los condes y marqueses del Pallars. Esa triple estructura se puede resumir así: 
1a.) Presentación de la institución propietaria del Archivo (en este caso, trazar la evolución histórica de los señores del Pallars que regentaron este estado pirenaico catalán a lo largo de los siglos).

$2^{a}$.) La formación del Archivo del condado y marquesado y su evolución posterior agregado progresivamente a distintas unidades archivísticas superiores.

$3^{\mathrm{a}}$.) Un resumen de los contenidos de la propia documentación del Pallars haciendo un ligero repaso de sus series más significativas.

\section{EVOLUCIÓN HISTÓRICA DEL CONDADO Y MARQUESADO DE PALLARS}

De la larga historia señorial del Pallars, me voy a centrar aquí, a grandes rasgos, preferentemente en la etapa medieval como estado "soberano» prácticamente independiente, o etapa condal, sin duda alguna la etapa histórica más gloriosa de esta comarca pirenaica catalana. Trazo esta evolución repasando algunas páginas recogidas de mi propia tesis doctoral.

El estado de Pallars, con originaria entidad de condado, fue uno de los dominios feudales que surgieron en la Cataluña naciente al tiempo de la expulsión de los musulmanes de los valles del Pirineo leridano. El de Pallars fue, pues, uno de los componentes de la llamada «Marca hispánica» carolingia en el siglo IX, situándose en estas tierras altas pirenaicas entre los también dominios condales vecinos de Ribagorza, por el oeste (con quien compartió sus primeros titulares), y de Urgell, por el este.

El condado estuvo regentado en sus orígenes, junto con el de Ribagorza - como decimos-, por los condes de Tolosa, cuyo dominio cesa en las últimas décadas del propio siglo IX creándose una dinastía indígena o autóctona fundada por el conde Ramon I ( ? -920), según las investigaciones principalmente de Ramon d' Abadal refrendadas en el volumen tercero de su "Catalunya Carolingia" - dedicado específicamente a los Condes de Pallars y Ribagorza-que después otros historiadores han ido completando. La muerte de este conde Ramon I en el año 920 va a originar la definitiva separación de los condados pallarense y ribagorzano, este último con una andadura independiente más bien corta pues acabaría incorporándose durante el primer tercio del siglo XI a la Corona de Navarra en tiempos del rey Sancho «el Mayor».

La evolución del condado de Pallars, por su parte, sería ciertamente mucho más larga y compleja por cuanto a lo largo de todo el siglo $X$ estuvo regentado de forma bipartita o tripartita, en razón del número de titulares en quienes recaía la sinarquía o gobierno compartido del dominio, hecho que originó a la muerte del conde Sunyer en el año 1011 la división definitiva del estado en dos partes, por reparto entre sus dos hijos: el Alto Pallars o Sobirà para Guillem II ( ? -1035) y para Ramon II ( ? -1097) el Bajo Pallars o Pallars Jussà. 
El Pallars Sobirà, cerrado al norte por el Pirineo francés, tendrá más allá de esta linde las tierras del condado de Tolosa en donde quedaron emplazados los estados de Comenge y de Foix; por el oeste tenía al valle de Arán en la zona septentrional y las tierras del condado vecino y hermano del Pallars Jussà que también lo bordeaba por el sur; y por el este lindaba con el condado de Urgell e incluso tocaba la zona montañosa próxima a Andorra. Se trata de una zona plenamente pirenaica en la cuenca alta del Noguera-Pallaresa, de valles más bien escasos en recursos aprovechables por entonces, lo que hizo llevar a sus titulares a un expansionismo hacia las tierras más bajas del sur en torno a la Conca de Tremp, que ya quedaba fuera de su jurisdicción.

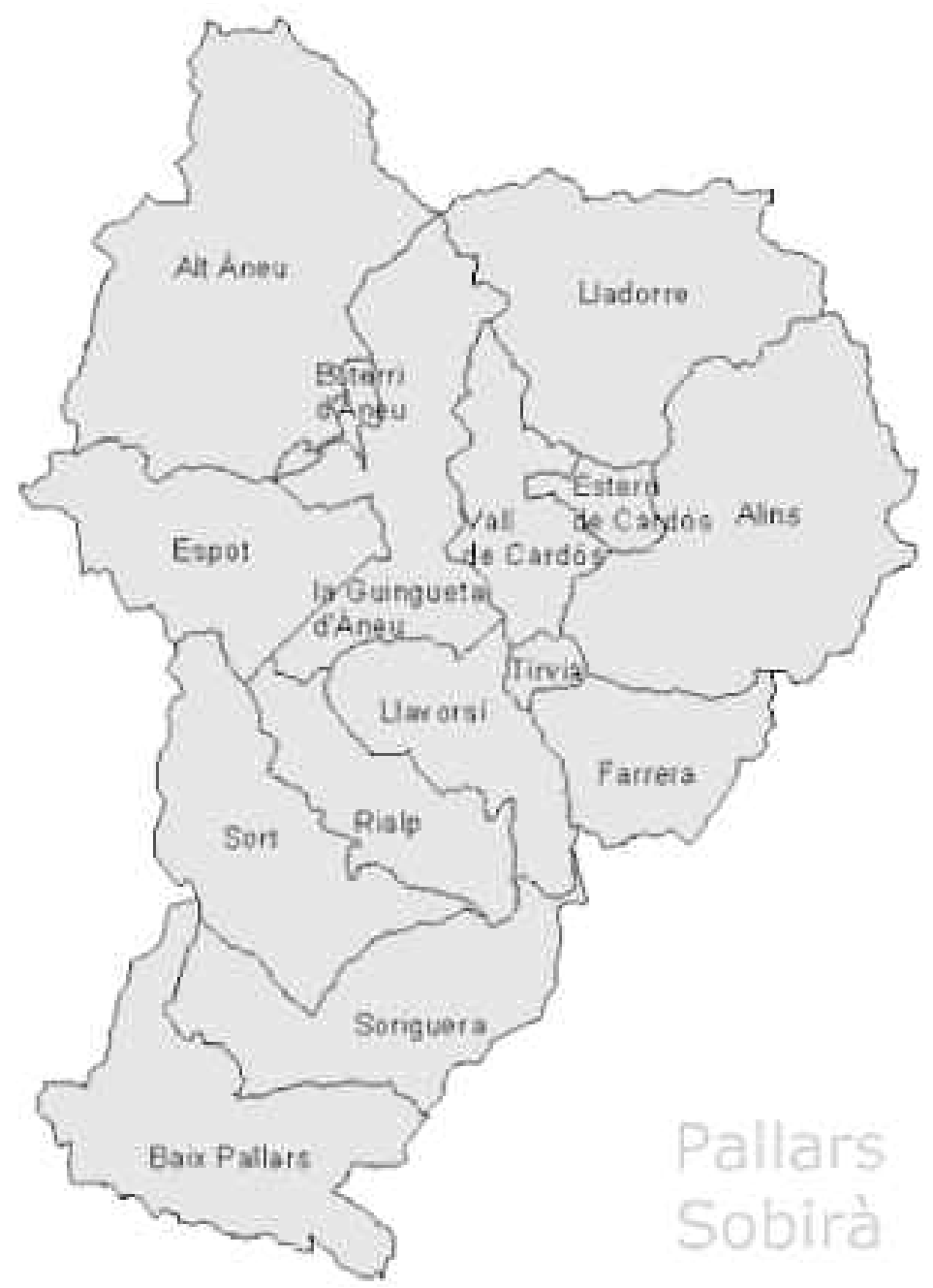

Fig. 1. Límites del condado de Pallars Sobirà. 
El Pallars Jussà ocupó la cuenca baja del mismo río Noguera-Pallaresa prolongándose por la Conca de Tremp hasta la sierra del Montsec que le daba su linde sur; por el norte entraba como una cuña, bordeando al alto condado hermano, hasta el mismo valle de Arán; por el este tocaba el sector suroccidental del condado de Urgell y por el oeste era el Noguera-Ribagorzana quien le daba los confines de poniente, lindando con las tierras de la Corona de Aragón, que lo bordeaban tanto por esta zona como por el sur.

Este Bajo Pallars reunía mejores condiciones de habitabilidad y es, por ello, por lo que contaba con una densidad demográfica mayor que su hermano del norte; también contaba con mayores recursos y, además, con mejores posibilidades para poder expandirse Noguera abajo. Por esta razón, se trataba de un dominio más peligroso en cuanto a su defensa. Tal vez todo este cúmulo de circunstancias

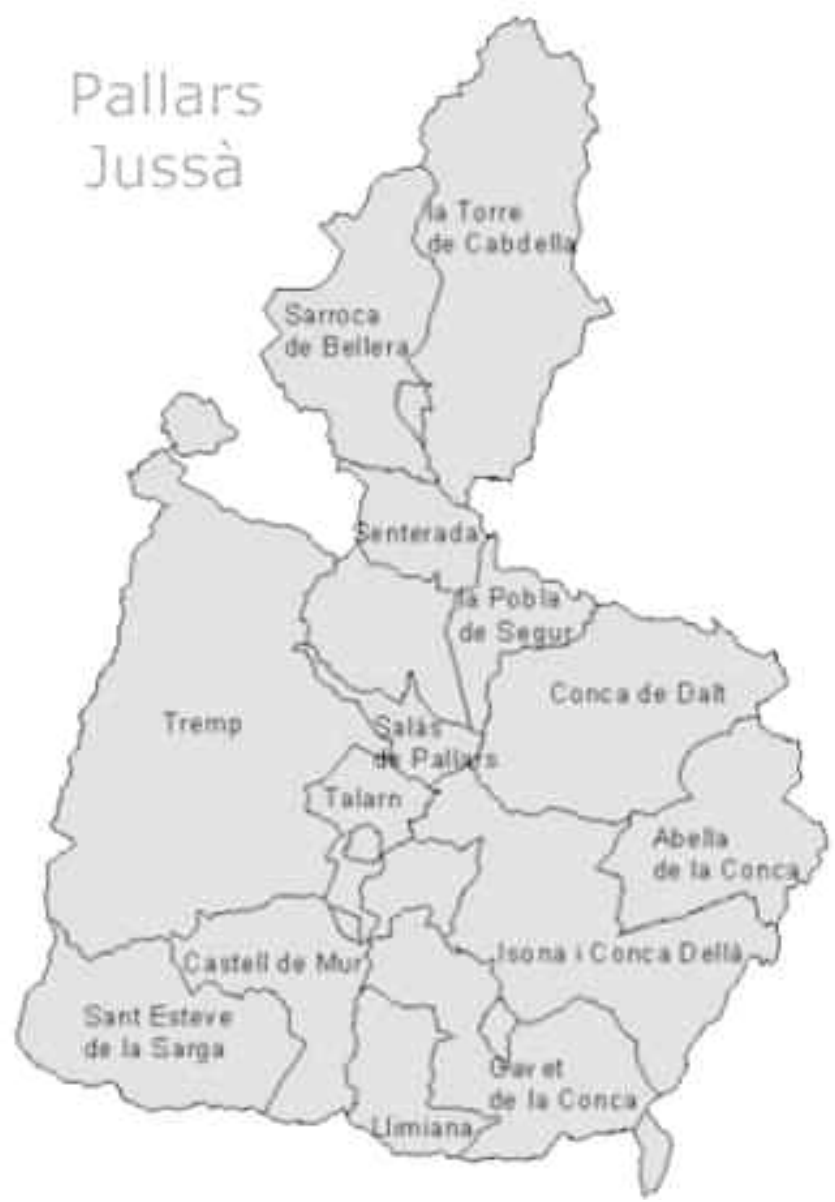

Fig. 2. Límites del condado de Pallars Jussà. 
fueron las que le dieron una más corta existencia al condado de Pallars Jussà, pues apenas tendría ochenta años de vigencia su trayectoria autóctona. A la muerte del conde Ramon V, descendiente de aquel Ramon III y esposo desde 1167 de la vizcondesa de Cardona Anglesa Folc, pasaba efímeramente este estado pallarense del sur a Valença de Pallars, hija de un primer matrimonio del conde. Pero esta señora falleció muy joven como condesa de Pallars Jussà, pasando entonces el dominio a manos de una tía suya, $D^{a}$. Dolça de So, ya de edad avanzada y sin descendencia, que cedió en 1192 el dominio al rey Alfonso II de Aragón. Con esta incorporación a la Corona aragonesa finalizaba la etapa de gobierno soberano del condado meridional del Pallars.

El condado del norte, por su parte, o Pallars Sobirà, prolongaría mucho más allá su existencia soberana en los descendientes del ya aludido Guillem II y, cuando quedó extinto su vecino hermano en tiempos del conde Bernat II ( ? -1199), a partir de entonces se denominaría por antonomasia con el nombre originario de Condado de Pallars, tomando una parte del territorio que antes fue Pallars Jussà. Casi de inmediato, el 6 de marzo de 1229, la hermana y sucesora de Bernat, Guillerma de Pallars ( ? -1250) traspasaba en venta el condado a su propio esposo Roger de Comenge ( ? -1256), por 15.000 maravedíes o morabatines de oro y luego se retiraba a la vida monástica en el convento de Santa María de Vallbona.

Se extinguía así la antigua dinastía que había gobernado el Pallars durante más de dos siglos pero el condado conservaba su autonomía, ahora en poder de la familia gala de «Comenge». Esta separación matrimonial posibilitó que el conde Roger de Pallars contrajera nuevas nupcias hacia 1235 con Sibilla de Saga, de la Casa de Cerdanya-Berguedà, de quien nació su sucesor Arnau Roger I ( ? -1288), uno de los magnates que más colaboraron con la Corona durante el reinado de Alfonso III de Aragón. De los dos matrimonios contraídos por este conde, sólo el segundo, que mantuvo con la princesa griega Láscaris - hija del emperador de Nicea Teodoro II-, le dejaba descendencia, en este caso femenina, cuando aquél fallecía en 1288.

Por ello, tras una etapa de regencia del condado entre dicho año de 1288 y el de 1295 por parte de Ramon Roger I, hermano de Arnau, va a suceder en el estado pallarense - no sin problemas - la mayor de sus hijas, llamada Sibilla de Comenge ( ? -1330), esposa para entonces de Hug de Mataplana. Una vez que enviuda de éste en 1328, la condesa asocia al gobierno del estado pallarense a su primogénito Arnau Roger, a quien el año antes había instituido como su heredero universal por vía testamentaria.

Fue así como de nuevo el histórico condado de Pallars vuelve a cambiar de dinastía, por la de «Mataplana», cuando a la muerte de $\mathrm{D}^{\mathrm{a}}$. Sibilla en 1330 ya de forma efectiva Arnau Roger II ( ? -1343) accede al gobierno de este estado pirenaico. Una dinastía, la de Mataplana, que no en la posteridad de éste — pues Arnau II careció de posteridad descendencia en los tres matrimonios que contrajo- pero sí en la de su hermano Ramon Roger II ( ? -1350), que obtuvo el condado gracias a la ayuda del rey aragonés Pedro III tras pleito con su otro hermano Roger Bernat, tuvo prolongación postrera hasta la extinción del condado a fines del siglo XV. 


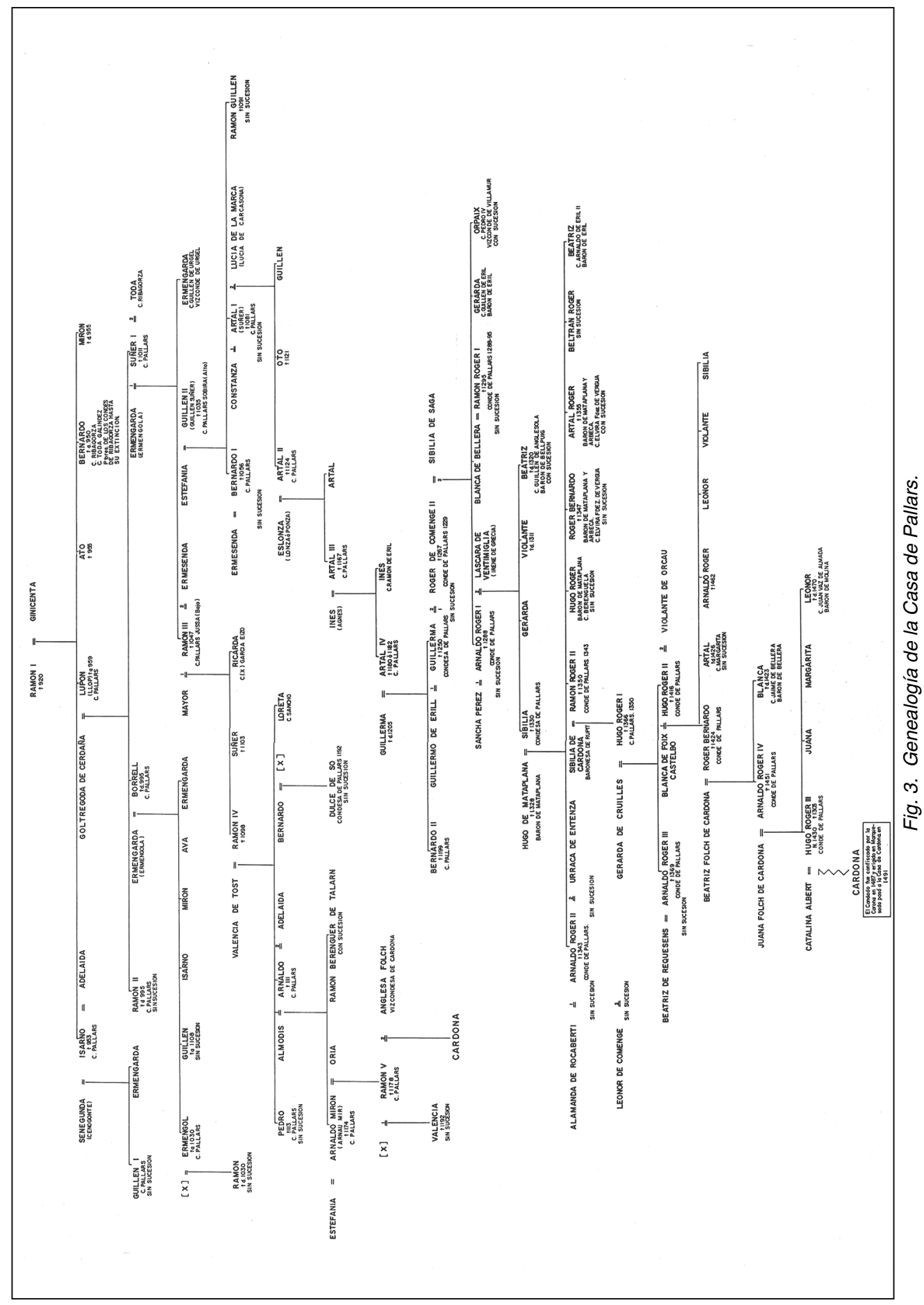


No se ha dado aún la justa medida del último de los condes de Pallars, el polémico Hug Roger III (1430-1503), considerado — por unos- en la historiografía como el gran traidor, cruel e indomable soldado y - por otros- como el héroe y hombre enérgico e incorruptible. Tal vez en esta antagónica visión del personaje, sin duda alguna uno de los más destacados de su tiempo, resida su grandeza, «la grandesa tràgica - que diría Sobrequés- del darrer dels comtes del Pallars». Su pertinaz lucha contra la dinastía reinante en la Corona de Aragón y Principado de Cataluña (que hemos de encuadrar dentro de las guerras civiles promovidas por entonces), taladra el eje de su biografía y fue lo que, a la postre, determinó su caída. Vencido por las tropas reales en 1487, Hug Roger III hubo de expatriarse (a Francia e Italia) y su estado de Pallars fue confiscado por el rey Fernando «el Católico" y vendido un año después al conde de Cardona, Joan Ramon Folc IV, por 36.000 libras barcelonesas, de las que sólo debía aportar 12.000, en premio a los servicios prestados en la conquista del territorio por su padre, el anterior conde Joan Ramon Folc III y almirante del reino, y por él mismo cuando, como heredero de la Casa de Cardona, era conde de Prades y Condestable de Aragón. De inmediato, en 1489, el conde tomaba posesión de su nuevo estado y, poco después, por privilegio dado en Sevilla el 7 de abril de 1491 el mismo monarca, en consideración a la nobleza, antigüedad y grandeza de la Casa de Cardona y al valor y la lealtad mostrados, elevó el condado de Cardona a ducado al mismo tiempo que erigía en marquesado el histórico condado de Pallars.

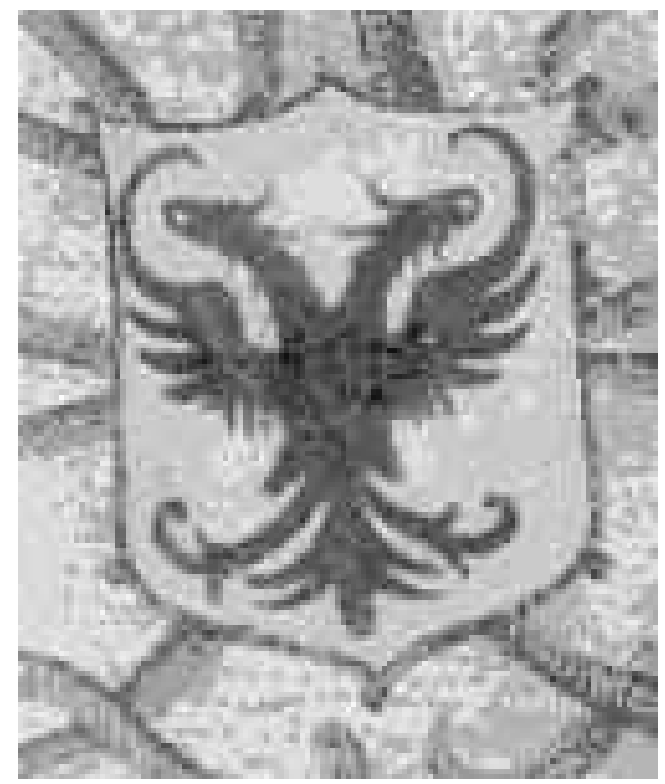

Fig. 4. Escudo de armas de los condes de Pallars. 
Fue así como, en adelante, se perpetuó este estado pirenaico en poder de la Casa de los «Folc de Cardona», tras acabar el rey Católico con el sueño del último Conde de Pallars, conocido como el señor de las montañas, de crear un estado pirenaico. Hace algo más de quinientos años Hug Roger III de Pallars murió prisionero en una celda del castillo de Xàtiva, como último representante de la estirpe condal más duradera de la historia de Cataluña.

Para entonces los límites geográficos del estado se habían estrechado considerablemente con respecto a sus perfiles originarios. No se olvide que la parte sur del condado, el Bajo Pallars, había revertido a la Corona aragonesa a fines del siglo XII. De esta forma el recién creado marquesado de Pallars entraba en los tiempos modernos con una configuración territorial bien distinta, que es la que nosotros recogemos seguidamente en el mapa adjunto, perdiendo la continuidad espacial que había caracterizado al estado en la anterior etapa condal. Sin embargo, hemos de hacer constar que, aunque efectivamente los dominios se habían estrechado, al menos todo lo que fue el Alto Pallars permanecía en poder de la Casa (ahora la de Cardona como marqueses de Pallars), bien en plena jurisdicción -que son los términos que recoge el referido mapa - o bien como feudatarios de los señores - que son las zonas que aparecen sin sombrear-.

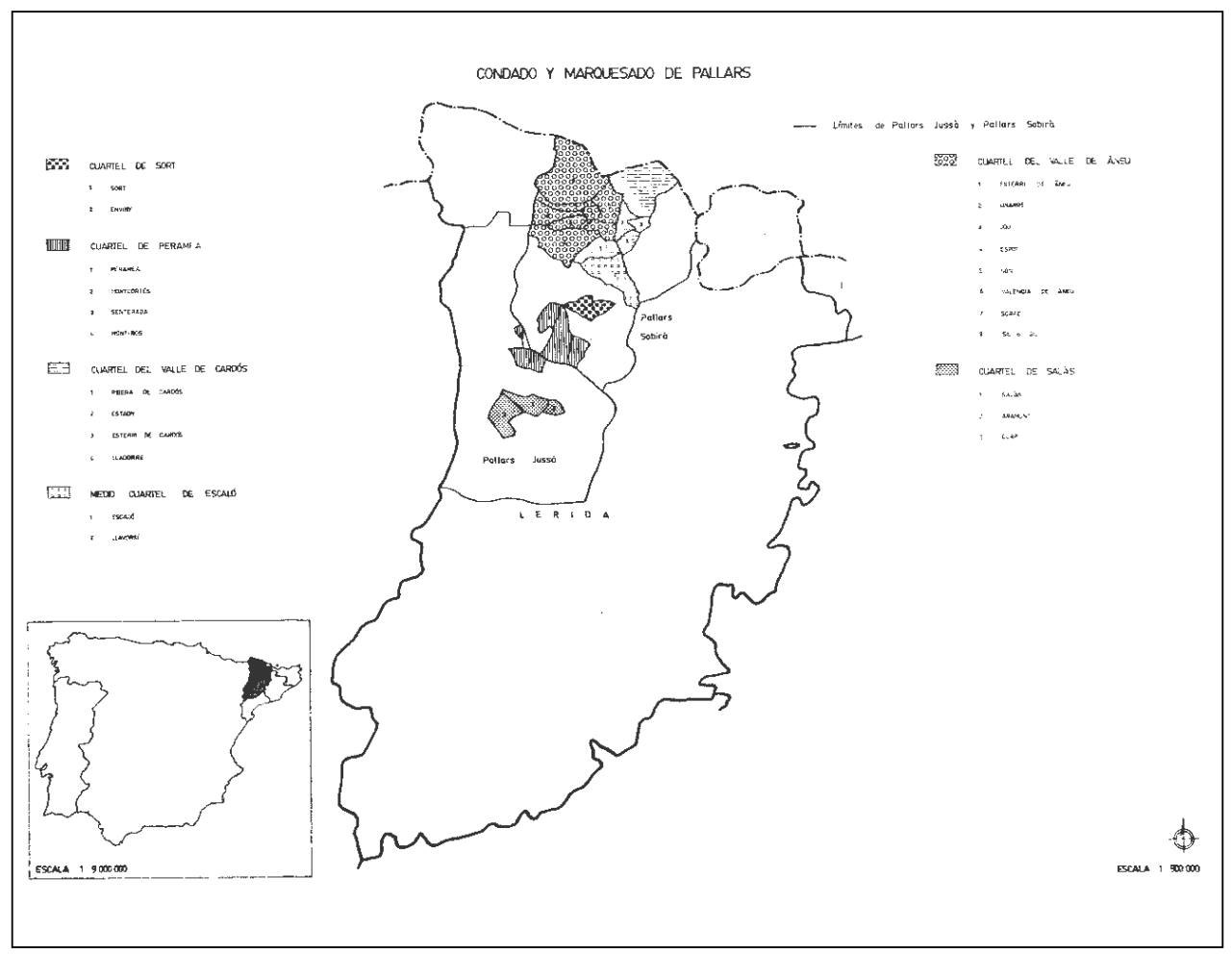

Fig. 5. Mapa del condado y marquesado de Pallars con sus territorios feudatarios. 
El marquesado pallarense quedó dividido, a instancia de los nobles titulares, en seis demarcaciones o cuarteles jurisdiccionales y administrativos, a saber:

1) El primero, el del valle d'Àneu, en el ángulo noroccidental del estado y con capital en la villa de Esterri d'Àneu. Un valle atravesado por el curso inicial del Noguera-Pallaresa y por sus primeros afluentes (Bonaigua, Unarre, etc.) y contorneado por altísimas sierras: al norte, los picos de Sernella, Clavera y los puertos de Aulà y Salau; que les separan de la región francesa de Coserans; al oeste, el coll del Marimayna, Rosari, el puerto de Bonaigua, coll de Sant Maurici y Portarró d'Espot que le separan del valle de Arán; al sur, Saburó, Peguera, Monestero y Encantats; al este linda con el valle de Cardós, nuestra próxima demarcación. Dentro del valle se emplazaban, formando parte de este cuartel jurisdiccional del marquesado, las villas y lugares de: Esterri d'Àneu, Son, Espot, Alós (con la Bastida), Isil o Gil, Borén, Servi, Jou, Dorve, Berrós Jussà y Sobirà, Isavarre, Sorpe, Escalarre, València d'Àneu (posible residencia condal) y Unarre.

2) El segundo cuartel lo constituía el valle de Cardós, en el ángulo nororiental del estado y con capital en la villa de Ribera de Cardós. Un valle cursado por el afluente del Noguera-Pallaresa que de él recibe el nombre de Noguera de Cardós, con límite norte en los puertos de Tavascán y Lladorre y en el pico de Estats. Al este tiene el valle de Farrera, también feudatario del estado. $Y$ por el sur lindaba con la próxima demarcación. Dentro del valle, además de la capital, Ribera de Cardós, se emplazaban los lugares de Surri, Bonestarre, Estaon, Ainet, Arrós, Esterri de Cardós, Ginestarri, Lladrós, Lladorre, Boldís Jussà y Sobirà, Tavascan, Nas y Cassibrós.

3) La tercera demarcación administrativa, denominada en época marquesal medio cuartel de la villa de Escaló, además de esta villa que constituía su cabecera, contenía los lugares de Llavorsí, Aidí, Estaron, Escart, Sant Pere de Burgall y Baiasca. Su situación se la daba el límite sur de los dos valles susodichos d'Àneu y de Cardós y, por tanto, se hallaba en la zona central del estado.

4) Tras un estrecho pasillo de separación se emplazaba el cuartel de Sort, que tenía a esta villa como su cabecera, y que ocupaba la llamada Ribera de Sort, al sur del valle d'Assua y con límite, por el este, con el vizcondado de Vilamur. Además de Sort, de dicha demarcación dependían las poblaciones de Bernui o Pernui, Vilanflor, Olp, Pujalt, La Bastida de Sort o de Castellvell, Castellvell o Castellvill, Enviny y Montardit.

5) El quinto cuartel era el de Peramea, en cuyo ámbito se administraban los dominios más meridionales del Pallars Sobirà y algunos próximos y colindantes del Pallars Jussà que también habían quedado en poder de los antiguos condes. Esta demarcación se emplaza así en la Vall Fosca, junto a los límites de La Pobla de Segur (otro ámbito de jurisdicción del vizcondado de Vilamur). Además de Peramea, este distrito administraba las villas y lugares de Montcortès, Sellui, Senterada, Puigcerver, Lluçà, Montsor, Castellnou, Sossís y montaña de Bayarí, Brenui, Pobellà, Paüls (de Flamicell) y Mont-ros, más los despoblados de Plans de Corts y Montíos. 
6) Por último, como sexta demarcación administrativa del marquesado de Pallars, se hallaba el cuartel de Salàs, bastión más meridional del estado que quedaba separado del distrito jurisdiccional anterior por el referido término de La Pobla de Segur. Se hallaba así en el límite norte de la conca de Tremp, al oeste de la sierra del Boumort, obviamente dentro del Pallars Jussà. Este cuartel tenía a la villa de Salàs, de la que recibía el nombre, por capital, y además administraba las poblaciones de Gurp (de la Conca), Santa Engràcia, Sant Joan de Vinyafrescal, Aramunt y Pessonada, y los ya despoblados lugares de Mas de Balust, Castell Enclús, Castellat y Miret.

Formaba así la totalidad del marquesado de Pallars un conjunto de dominios cuya extensión rondaría los $950 \mathrm{Kms}$. cuadrados.

Con tales perfiles territoriales encaraba la Edad Moderna este estado pirenaico, ya como agregado a la Casa de Cardona, una casa nobiliaria catalana que, con ésta del Pallars y otras muchas agregaciones anteriores de dominios forjados durante la época medieval, afrontó la Modernidad con una extraordinaria fortuna y una opulencia que contrastaba con la decadencia en la que se vieron sumidos por entonces la mayor parte de los antiguos grandes linajes catalanes. Si a todos éstos les afectó de manera insalvable la profunda crisis económica y política del período bajo-medieval, la Casa Ducal de Cardona, con el Pallars, —como ya dijimos- se permitió adentrarse en los albores de la Modernidad encumbrada en el momento más álgido de su poderío. Y, si aún cabía más, a lo largo del Quinientos va a verse aún más realzada al entroncar, por alianza, con la Casa de los Duques de Segorbe y Condes de Ampurias - surgida en el seno de la propia Casa Real aragonesa- merced al matrimonio que, en 1516, contrajeron el heredero del ducado de Segorbe, D. Alonso de Aragón, conde de Ampurias, con la heredera o «pubilla» del ducado de Cardona, $D^{a}$ Juana Folc, tras capitulaciones dadas en la ciudad de Segorbe el 30 de abril de dicho año. El primero en heredar los estados de su Casa fue D. Alonso de Aragón (1489-1593) que, a la muerte de su padre el «Infante Fortuna» D. Enrique en 1522, se convertía de manera efectiva, en II Duque de Segorbe (aunque fue el primero que se tituló así), Conde de Ampurias, Señor de Vall de Uxó, Sierra de Eslida, Paterna, Benaguacil, La Pobla de Vallbona, etc. Años más tarde, en 1543, por muerte sin descendencia masculina del segundo Duque de Cardona D. Ferran Ramon Folc, sucedía en sus estados la primogénita $D^{a}$. Juana Folc I (1504-1564) convirtiéndose desde entonces en la III Duquesa de Cardona, III Marquesa de Pallars, VIII Condesa de Prades, Vizcondesa de Vilamur y Señora, entre otros lugares, de las baronías de la Conca de Òdena, Juneda, Arbeca, Entenza y Oliola.

El heredero de tan amplios y singulares estados patrimoniales fue un hijo del matrimonio integrador, llamado $\underline{D}$. Francesc Ramon Folc (1539-1575), quien desde la muerte de su padre en 1563 se tituló, como tal, III Duque de Segorbe, Conde de Ampurias, etc. y, a partir del año siguiente en que finalizaron los días de su madre, se convirtió además en IV Duque de Cardona, Marqués de Pallars y los restantes títulos agregados. Luego recayeron estos grandes dominios, tras tener que 
soportar algunos problemas sucesorios, en su hermana $\mathrm{D}^{\mathrm{a}}$. Juana de Aragón (a.1539-1608), la fémina de mayor edad y con mejor derecho a la sucesión en ausencia de varón. Ésta era para entonces Marquesa consorte de Comares por el matrimonio que había contraído veinte años atrás con el tercer titular de este estado andaluz, D. Diego Fernández de Córdoba IV (1524-1601), llamado «el Africano». Modificando los apellidos, por exigencia de la reglamentación del mayorazgo, $D^{a}$. Juana Folc de Cardona y Aragón II se convertía así en IV Duquesa de Segorbe, $\mathrm{V}$ de Cardona, Marquesa de Pallars y demás títulos, que añadía por derecho propio al de Marquesa de Comares. El propio marqués D. Diego, para titularse Duque de Segorbe y Cardona hubo de modificar también sus apellidos dándole prioridad al de «Folc de Cardona» de su esposa. De esta manera quedaba integrada la Casa de los Marqueses de Comares, antes denominada Casa de los Alcaides de los Donceles por el cargo que estos nobles ejercían en la corte castellana, en la Casa Ducal de Segorbe-Cardona pues, aunque no cabe duda de que quien dio varonía a la posteridad fue el linaje «Fernández de Córdoba» de los Comares, la mayor relevancia y el poderío de la Casa Segorbe-Cardona (con el estado de Pallars como agregado) hizo que aquélla quedara en un segundo orden. Incluso, por imperativo del mayorazgo de la doble Casa Ducal, aunque los descendientes de este matrimonio usaron en primer lugar el apellido andaluz de la varonía, los herederos en adelante siempre hubieron de anteponer los apellidos «Folc de Cardona» y «Aragón».

Esta fusión de estados suponía la primera ampliación en tierras castellanas de la Casa de Segorbe-Cardona. Ello implicó, sin duda, una progresiva desvinculación de sus titulares del Principado de Cataluña, hecho por otro lado ya muy generalizado pues afectaba a la mayoría de las antiguas Casas nobiliarias catalanas. Los duques $\mathrm{D}$. Diego y $\mathrm{D}^{\mathrm{a}}$ Juana estuvieron afincados mayoritariamente en sus posesiones andaluzas y el contacto en sus dominios del norte se produjo a raíz de la dificultad que tuvieron, en algunos casos, para hacer valer sus derechos a la sucesión. Por ello, acudió D. Diego a las cortes convocadas en Barcelona por el recién entronizado monarca Felipe III en el verano de 1599, donde como duque de Segorbe y Cardona presidió la representación de los nobles y caballeros o brazo militar. La duquesa $\mathrm{D}^{\mathrm{a}}$ Juana, viuda ya del marqués de Comares, fallecía en agosto de 1608 y dejaba por vía testamentaria como único heredero a su nieto Enrique, ya que su primogénito el conde de Prades D. Luis Fernández de Córdoba Folc de Cardona y Aragón (1568-1596) —padre de aquél- había fallecido en vida de sus progenitores siendo por ello tan sólo transmisor del mayorazgo. Este D. Enrique Ramón Folc de Cardona y Aragón (1588-1640) se convertía así, al principiar el siglo XVII, en V Duque de Segorbe, VI de Cardona, VI Marqués de Pallars, IV de Comares, Conde de Ampurias y de Prades, Vizconde de Vilamur y Señor de un gran número de villas y lugares repartidos por Cataluña, Andalucía y el reino de Valencia. Siendo Capitán General del Principado en la agitada época de los inicios de la revuelta independentista catalana de 1640, fallecía en Perpiñán el 22 de julio de ese mismo año y le sucedía en tan importantísimos estados familiares su primogénito $\underline{D}$. Luis Ramón Folc de Cardona y Aragón (1608-1670), quien por ello se 
tituló desde entonces VI Duque de Segorbe, VII de Cardona, V Marqués de Comares, VII de Pallars, Conde de Ampurias y Prades, Vizconde de Vilamur, etc. Para entonces se hallaba desposado con $D^{a}$. Mariana de Sandoval y Rojas (16141651), muy pronto III Duquesa de Lerma, VII Marquesa de Denia, III Condesa de Ampudia, V de Santa Gadea, XI de Buendía y Señora también de un buen número de villas y lugares castellanos y de la dignidad del Adelantamiento Mayor de Castilla. Mas la prematura muerte en 1651 de la duquesa de Lerma, que dejaba descendencia, hizo al duque Luis Ramón contraer nuevas nupcias, nueve años más tarde, con $D^{a}$ María Teresa de Benavides Dávila y Corella, de la Casa de Santisteban del Puerto, con quien igualmente tuvo posteridad. Fue así como, a la muerte del duque en 1670, sucedió efímeramente en los estados de la Casa de Segorbe y Cardona el hijo de este segundo enlace matrimonial, $\underline{D}$. Joaquín Folc de Cardona y Aragón (1667-1670), quien sólo tuvo posesión de la misma por espacio de casi tres meses y cuando no había aún cumplido los tres años de edad.

Quedaba entonces la sucesión de la Casa en situación harto comprometida pues, no existiendo otro varón entre la prolífica descendencia dejada por D. Luis Ramón en sus dos matrimonios, solicitaron la posesión de la Casa, por un lado, el hermano del referido duque (llamado D. Pedro Antonio de Aragón) y, por otro, la mayor de sus hijas - hermana consanguínea del último y efímero titular- $\mathrm{D}^{\mathrm{a}} \mathrm{Ca}$ talina Antonia de Aragón. Entre ambos aspirantes se promovió un pleito por la sucesión de los estados. La sentencia fue favorable a $D^{a}$ Catalina influyendo sin duda en ello la retirada de la demanda interpuesta por el propio D. Pedro Antonio en razón a que había convenido matrimonio con una hija (sobrina-nieta suya) de su oponente. Llamándose por los imperativos del mayorazgo $D^{a}$. Catalina Antonia Folc de Cardona y Aragón (1635-1697) se tituló desde entonces VIII Duquesa de Segorbe, IX de Cardona, VIII Marquesa de Comares, aparte de la larga nómina de títulos y dignidades agregadas a estas importantísimas Casas. Para entonces y desde 1653 ésta se hallaba desposada con $\underline{D}$. Juan Francisco de la Cerda y Enríquez de Ribera (1637-1691), VIII Duque de Medinaceli, VI de Alcalá de los Gazules, Marqués de Cogolludo, de Tarifa y de Alcalá de la Alameda, Conde de El Puerto de Santa María, de Los Molares, etc.

Así fue como a partir de 1670 la doble Casa Ducal de Segorbe-Cardona, con el histórico estado pirenaico de Pallars agregado, pasaba definitivamente al patrimonio de los Medinaceli, en donde permanece en la actualidad. A su vez, durante este último espacio de tiempo la cadena de sucesivas agregaciones, y consecuente ampliación de los estados y bienes de la familia, no se interrumpió y los Medinaceli siguieron ampliando su patrimonio de una manera impresionante durante estos últimos siglos.

Repasando, no obstante, la evolución que acabamos de concluir comprobamos que el estado de Pallars, que había sido de los condes de Tolosa, de la propia Casa de Pallars, de los Comenge, de los Mataplana, de los Folc de Cardona, de los Fernández de Córdoba..., quedó vinculado a lo largo del tiempo con una gran cantidad de títulos y dominios. Pero cuando venía a estas tierras pirenaicas el Du- 
que de Medinaceli, desde el momento que entraba en las altas tierras del Pallars ya era el marqués de Pallars quien actuaba.

\section{GÉNESIS Y EVOLUCIÓN DEL ARCHIVO DE PALLARS}

En sus orígenes los archivos nobiliarios, en cuanto a contenedores documentales, no eran más que un baúl o unas arcas itinerantes llenas de pergaminos y papeles. Un archivo, por su contenido, siempre viene a ser un arsenal jurídico y, como tal, conserva los documentos que - se sabe o se intuye- en adelante van a necesitarse para probar y garantizar la defensa de las propiedades, regalías y prebendas de sus titulares; por eso, los que más poseen son los que más necesitan tener este modo de defensa.

Precisamente por esta necesidad de gestión nacieron, pues, todos los archivos y evidentemente también nació el Archivo Condal del Pallars, del que se desconoce con exactitud su sede inicial, aunque debió ser la misma donde en principio quedó establecida la corte y administración condal. Las escasas noticias que se han dado al respecto son, en realidad, muy poco rigurosas. Entendemos que la documentación pallaresa debió ser efectivamente custodiada por los condes al menos a partir del siglo XI, e intuimos que dos centurias después debió existir el archivo ya conformado y ubicado, según algunos, en el castillo de València d'Àneu. Sin embargo, se puede considerar que el emplazamiento del Archivo Condal bien pudo radicar en la fortaleza de esa villa o bien en los castillos de alguna de las restantes villas cabeceras de los diversos cuarteles que conformaron el ámbito territorial del Pallars: Sort, Peramea, Ribera de Cardós, Salàs, Escaló o Esterri d’Àneu... con mayores posibilidades en las primeras de las poblaciones reseñadas.

En cualquiera de los casos, las noticias sobre el fondo pallarense comienzan a tener respaldo documental (por vía de suscripciones de copias testimoniadas) a partir de la incorporación del estado a la Casa de Cardona en los años finales del siglo XV, al tiempo de su constitución en marquesado. Desde entonces para acá se conoce perfectamente su evolución, como he dejado escrito en algunas de mis publicaciones reseñadas en la bibliografía que recogemos al final. El Archivo de Pallars se trasladó de inmediato a la fortaleza de la villa de Cardona, reuniéndose con los fondos que esta Casa tenía ya instalados en dicho emplazamiento. Muy probablemente repercutió en este pronto traslado la forma anormal de incorporación del estado pirenaico al patrimonio de la familia «Folc de Cardona», aunque la medida se ajustaba a la vez al plan de centralización de archivos que a lo largo del siglo XVI la Casa de Cardona puso en ejecución. El hecho es que, en los años centrales del Quinientos, la documentación del estado de Pallars ya se encontraba instalada en el castillo cardonense formando una sección particularizada dentro del depósito. Allí, los documentos del fondo se custodiaban en bolsas, cajas o cofres - in quodam techato- con una rotulación común bajo la leyenda "Dels actes del Marquesat de Pallars», y sabemos que tales documentos estaban ordenados con un número al dorso escrito en caracteres romanos. Esto no quiere decir que el resto del Archivo de Cardona tuviera la misma 
forma de ordenación, pero evidentemente el dato de que existían unos números romanos correlativos al dorso de los pergaminos pallareses significa que ya había un sistema de orden, a la vez que presume una clasificación previa.

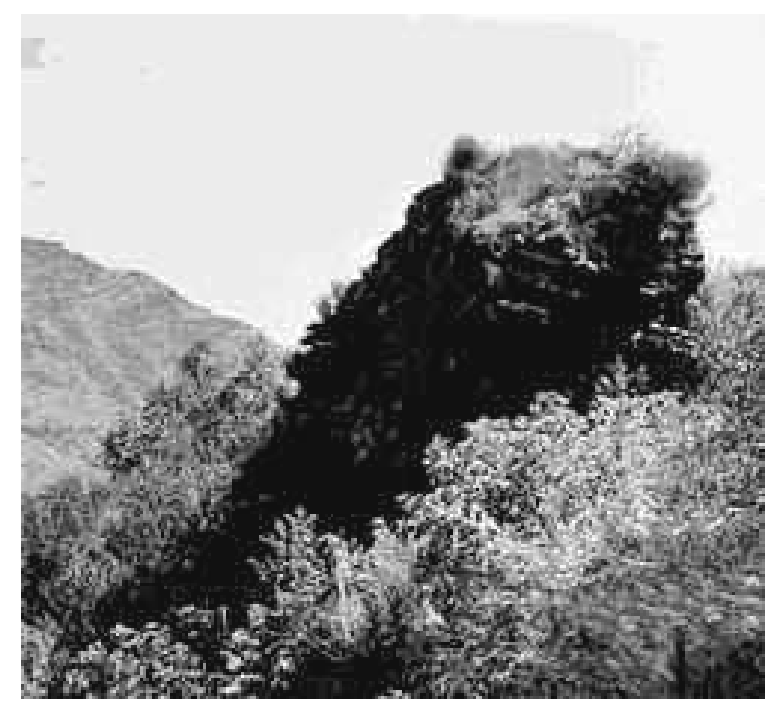

A

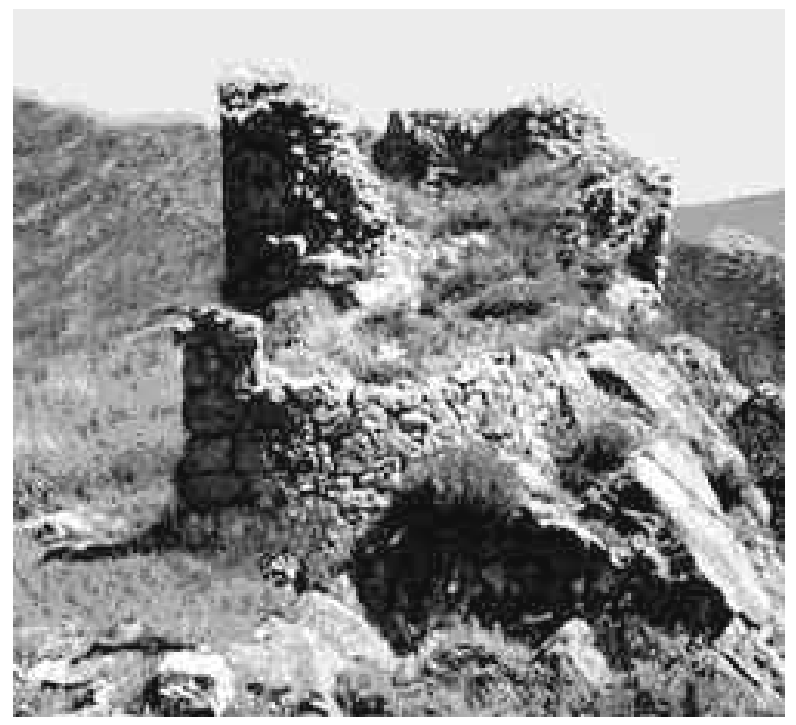

B

Figs. 6 A y B. Vestigios actuales de los castillos de València d'Aneu y Peramea. 
Podemos precisar, por tanto, que la Casa de Cardona supo concentrar su patrimonio documental en el Archivo central que dispuso en el castillo de la propia villa del mismo nombre pues, si bien no todos los aportes de escrituras que recibió llegaron entonces a reunirse allí, queda claro que la mayoría de ellos sí lo hicieron, donde permanecían instalados a lo largo de todo el siglo XVI. Esto va a significar que por entonces pueda hablarse ya, de alguna forma, de un "Archivo General» de la Casa de Cardona al referirse al archivo cardonense. A partir de entonces el archivo del Pallars se encuentra agregado a otros muchos: los del condado de Prades, la baronía de Entenza, vizcondado de Vilamur, baronías de la Conca d'Ódena, Arbeca, Juneda, Oliola, y todos los fondos de los estados que tenía vinculados la Casa de Cardona en aquel entonces por agregaciones seculares.

Más tarde, después del entronque de la casa de Cardona-Pallars con la de Ampurias-Segorbe, el ampliado Archivo General se establece en la villa de Arbeca. En 1621 los duques comienzan a dar órdenes a todos los gobernadores de sus estados para que fueran remitiendo las diversas remesas de fondos documentales de cada uno de los dominios con destino al castillo-palacio arbequino, donde quedó acondicionado el depósito en 1623. Sabemos incluso los nombres de las personas que se ocuparon del traslado de los fondos, con qué medios de transporte lo hicieron, cuántas mulas se emplearon, qué arrieros, cuántas arcas llevaban, los costes de algunos de los desplazamientos, etc.

El castillo de Arbeca, que ya apenas existe pues lamentablemente fue demolido en avatares bélicos posteriores, era entonces un inmueble de una gran suntuosidad, como prueba el hecho de que contaba con tantas rejas doradas

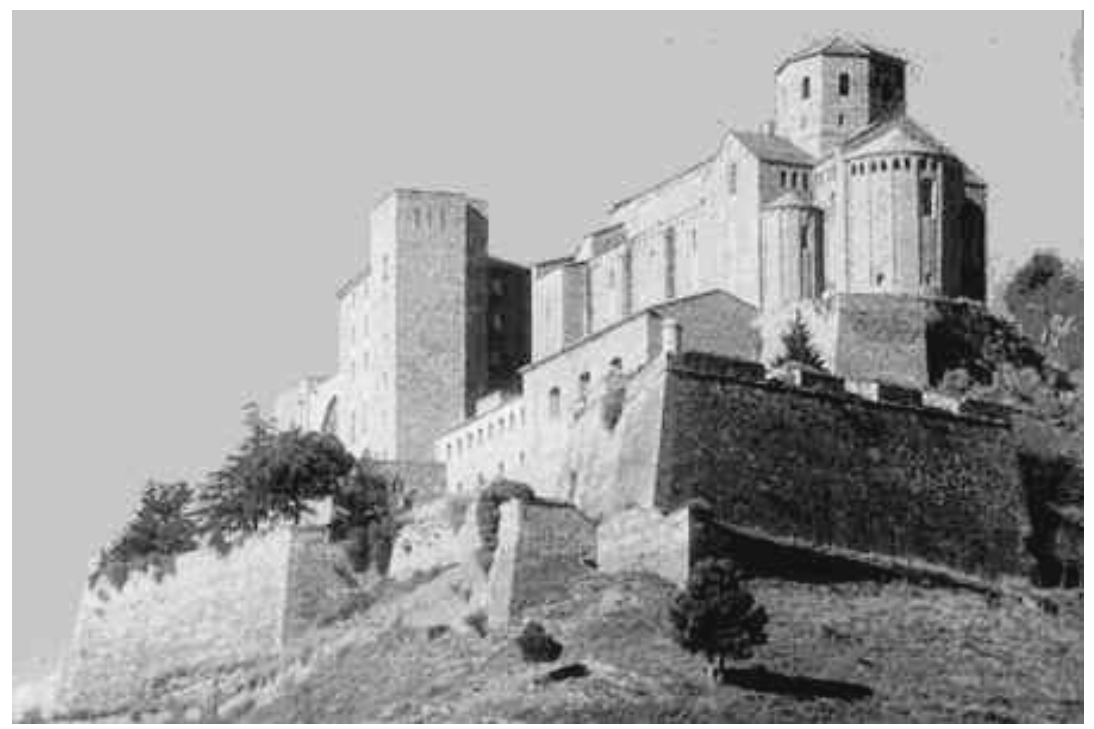

Fig. 7. Castillo de Cardona. 
como días tiene el año, que le daban al palacio-fortaleza de los Cardona un reflejo especial admirado a distancia por los contemporáneos. Este archivo arbequino empieza a conocer sus primeras agitaciones no mucho tiempo después, concretamente en 1640 cuando se desencadena la revuelta catalana conocida como «guerra dels Segadors». Para evitar problemas, durante la contienda el duque Luis Ramón Folc da la orden de traslado de la documentación a Andalucía, concretamente a la ciudad cordobesa de Lucena, capital de su estado de Comares, donde permanece algunos años a la espera de que se aclarara la situación del Principado para devolverla a Cataluña, cosa que ocurre efectivamente en 1660 cuando, tras la firma del tratado de paz de los Pirineos, el territorio queda en calma. Entonces el duque vuelve a dar una orden para que el Archivo retornara a Cataluña, aunque ahora el destino no va a ser Arbeca sino la villa de Falset en el Priorat.

En 1661 ya se hallaba toda la documentación ubicada en el primer piso del castillo de Falset ocupando dos salones: uno principal, que servía de depósito de los fondos, y otro salón, antesala del anterior, destinado al lugar de trabajo del archivero y sus ayudantes. Las tareas de traslado, acondicionamiento, instalación, organización y descripción de los fondos fue confiada por parte del duque D. Luis Ramón Folc de Cardona al notario de Castelló y del condado de Ampurias, Bernat Josep Llobet, funciones que supo cumplir a la perfección pues realizó una labor archivística encomiable desde todos los puntos de vista.

El período de estancia en Falset del Archivo de la Casa de Cardona (con el de Pallars como agregado) fue ciertamente largo pues se prolongó hasta mediados del siglo XVIII; en esa etapa hubo de soportar, en papel de gran protagonista, los sucesos de la guerra de Sucesión a la Corona española en Cataluña, sobre todo en la etapa final de resistencia a la soberanía borbónica.

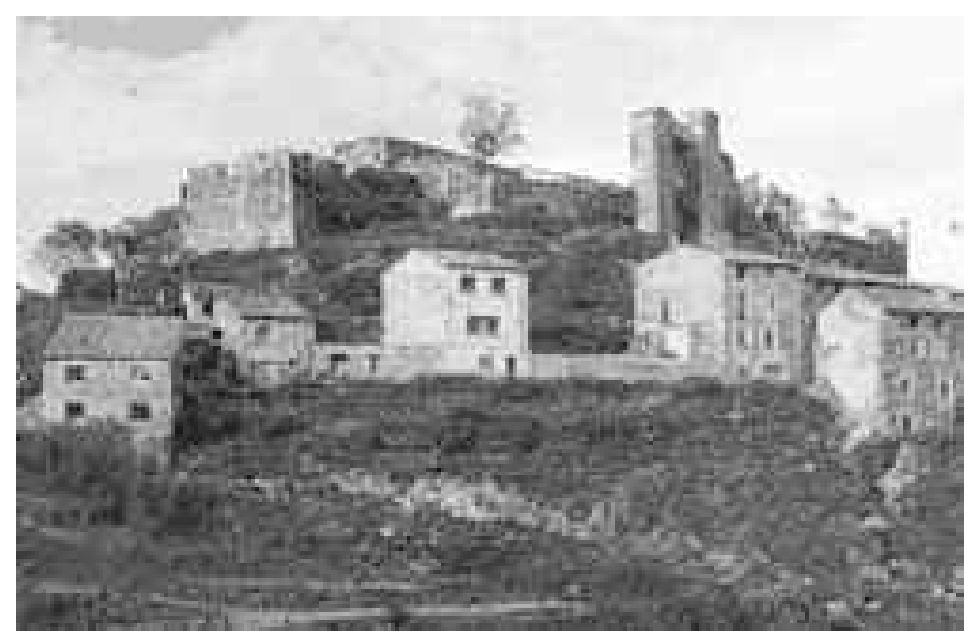

Fig. 8. Castillo de Falset, en la parte alta de la villa del Priorat. 
Años después, en 1747, el Archivo buscó ya el que sería su último emplazamiento en territorio catalán, dentro de la ciudad de Barcelona, concretamente en el «Palau o Casa Gralla» de la calle Portaferrissa, donde permaneció hasta los últimos días del año 1853. En ese impresionante palacio renacentista - también hoy inexistente aunque recompuesto parcialmente en otro lugar- atravesó el Archivo de la Casa Ducal de Medinaceli en Cataluña algunas vicisitudes. Por ejemplo, a principios del XIX durante la guerra de la Independencia (o del Francés, que llaman en Cataluña), toda la documentación debió ocultarse a los franceses cuando Napoleón pretende cobrar las copiosas rentas del duque después de declararlo reo de muerte y de emitir un decreto de confiscación de todos sus bienes. Como una medida auténticamente premonitoria, 40 años antes otro duque - bisabuelo del anterior- había dado unas instrucciones para el gobierno del Archivo y, en el artículo 18 de esa ordenanza, se recogía explícitamente que «siendo Barcelona puerto de mar y muy prolija a las guerras, quiero que se construya en los sótanos del palau Gralla una bóveda para que, en caso de necesidad, pueda ocultarse la documentación». Evidentemente, ante la posterior contingencia, allí escondieron la documentación durante los 6 años y medio que se prolongó la contienda, permaneciendo los fondos camuflados en aquellos sótanos de Portaferrissa. El duque de Medinaceli, dadas las circunstancias, obviamente había tenido que salir huyendo, refugiándose durante ese tiempo en Ceuta, y en Barcelona habían quedado el administrador y el archivero ducales. Gracias al celo de este último, los franceses no localizaron la documentación y tuvieron dificultades para poder percibir las rentas de los Medinaceli. De ese modo, el Archivo pudo salvarse aunque quedó en parte dañado porque la humedad acumulada en aquellos sótanos afectó a una porción importante de los fondos. Sin embargo, rápidamente se tomaron medidas para paliar el daño originado mediante la elaboración de medidas restauradoras y la confección de copias de los documentos más deteriorados.

Por diversos motivos, el 7 de diciembre de 1853, el duque D. Luis Tomás Fernández de Córdoba y Ponce de León daba la orden de traslado del Archivo desde la ciudad condal a Madrid, donde los Medinaceli tenían ubicado para entonces el Archivo Central de todos sus restantes y numerosos estados, excepto la documentación de Cataluña que ahora llegaba. Y en Madrid permanecerán ya unidos todos los fondos documentales hasta al año 1961 en que la actual Duquesa de Medinaceli, $D^{a}$. Victoria Eugenia Fernández de Córdoba y Fernández de Henestrosa, decide trasladarlos a Sevilla, dentro del palacio conocido popularmente como «Casa de Pilatos», su residencia habitual.

Finalmente, desde Sevilla, en el otoño de 1995 el Archivo de los Medinaceli (con los fondos del estado de Pallars integrados) se traslada parcialmente al «Palacio Tavera» de Toledo para quedar como depósito en la Sección Nobleza del Archivo Histórico Nacional, traslado que levantó una gran polémica en Andalucía. Ante la negativa del Ministerio de Cultura de recepcionar este depósito en tales condiciones, las secciones no andaluzas del Archivo - entre las que se encuentra obviamente la de «Pallars»— continúan emplazadas en esta sede toledana de la 
Fundación Casa Ducal de Medinaceli encontrándose aún no del todo operativas para el público investigador, a falta de resolución judicial de los contenciosos pendientes.

\section{ALGUNOS DATOS SOBRE LA DOCUMENTACIÓN DEL PALLARS}

Cuando los fondos del Pallars fueron organizados en 1662 por el archivero Bernat Josep Llobet, el número de pergaminos y papeles inventariados en ese momento era de 1617; poco después existen 1734 documentos y ésos son los que tiene la actual sección «Pallars» dentro del conjunto del Archivo Ducal de Medinaceli. Pero por aquel carácter ramificado y arborescente -al que antes aludíamos - también hay documentos pallareses - aunque muy puntuales- en esas otras secciones del depósito. saber:

Esta documentación se organizó en cinco grandes bloques de materias, a

$1^{\circ}$.) Todo lo relativo a «descendencia, sucesión y cosas domésticas» de los señores del Pallars, que son los fondos que trazan la evolución histórica de la transmisión de este antiguo dominio catalán.

$2^{\circ}$.) Los documentos referidos a «cosas comunes» de las distintas villas, lugares y castillos de todo el condado y luego marquesado pallarense.

$3^{\circ}$.) La documentación «particular» de cada enclave que componía el estado pirenaico.

$4^{\circ}$.) Los diplomas sobre «feudos» anexos al patrimonio familiar, casi siempre colindantes, que aunque no eran zonas de plena jurisdicción de los condes y marqueses del estado sí tenían dependencia de éstos.

$5^{\circ}$.) La documentación puramente administrativa y contable, como censos, enfiteusis, ápocas o cartas de pago, etc.

No podemos entrar aquí en más detalles, por exigencias de espacio de la publicación, sobre la documentación señorial del Pallars que se encuentra en el Archivo Ducal de Medinaceli, pero esta deficiencia queda salvada remitiendo al lector a la consulta de un artículo mío, que publiqué hace algunos años sobre el tema dentro del primer número de la revista Collegats, donde se contiene una guía general de todos los fondos del histórico dominio catalán.

\section{MUESTRARIO SOBRE LOS LIBROS MANUSCRITOS PALLARENSES}

El Archivo del condado y marquesado del Pallars, al margen de ese fondo documental específico de diplomas que hemos comentado anteriormente, contenía 
otra documentación, la referida a los libros manuscritos existentes sobre este enclave pirenaico, que por su amplio formato ha llegado a nuestros días - dentro de este amplísimo "banco de datos» que es el Archivo General de la Fundación Casa Ducal de Medinaceli- incluida en una sección facticia, muy variada, que se ha dado en llamar de "Libros manuscritos e impresos", en la que se conservan una cantidad importante de protocolos notariales, inventarios, pleitos, memoriales ajustados, capbreus o censales, libros de caja, etc.

Entre esa variedad de libros manuscritos existe un tomo de enorme valor archivístico y codicológico, como es el inventario o Recopilación que de la documentación pallaresa hizo el archivero catalán Bernat Josep Llobet en el año 1662. Su título completo es "Recopilación o Inventario de los autos y otras escripturas del Marquesado de Pallars. Compuesto de orden y mandato del Excmo. y por Real prerrogativa de su Real sangre, muy Illustre Señor Don Luis Ramon Folch de Cardona, olim de Aragón, Fernández de Córdoba, Duque de Segorbe y de Cardona, etc. Por Bernardo loseph Llobet, Notario y de número de los del Collegio de Notarios públicos de su villa de Castellón y Condado de Ampurias. Año 1662». Del manuscrito se conservan dos ejemplares de gran formato, ambos encuadernados en tablas de madera forradas en cuero y con utilización de pergaminos de códices anteriores medievales en las contraportadas, uno de 617 folios y el otro de 671 .

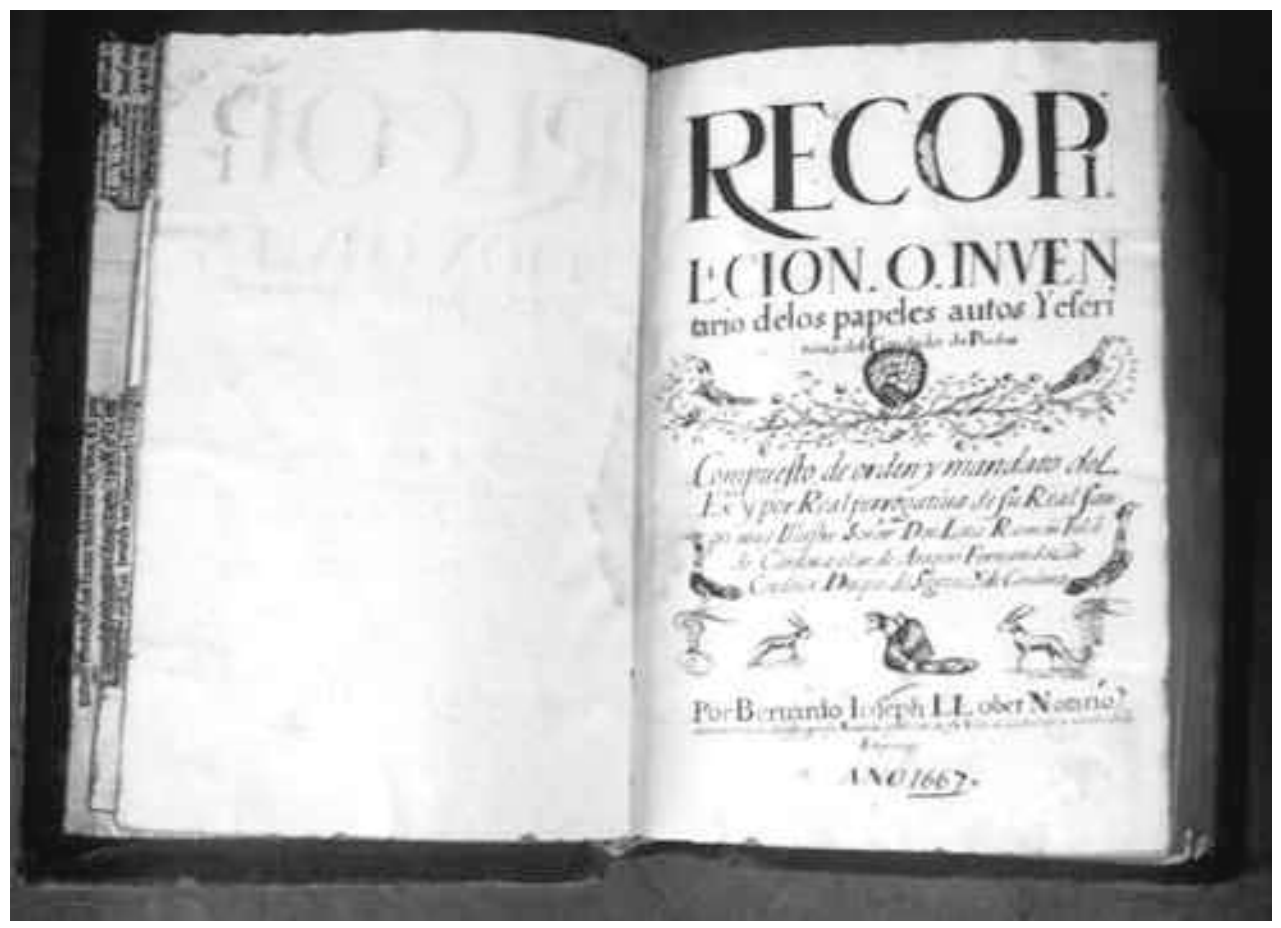

Fig. 9. Portada de uno de los inventarios del archivero B.J. LLobet . 
Las partes y otros caracteres de este interesante manuscrito son las siguientes:

a) Tras el título general y un escudo de la Casa Ducal pintado en pergamino, sigue una breve aclaración para el manejo de la obra, que llama Llobet «declaración de algunas cosas de dicha recopilación o inventario y del orden que se ha de guardar para buscar y hallar en dicha recopilación y en el Archivo las cartas que serán menester» y que no es otra cosa que una explicación de los pasos que habían de darse para la búsqueda y localización de un determinado documento dentro del fondo pallarense.

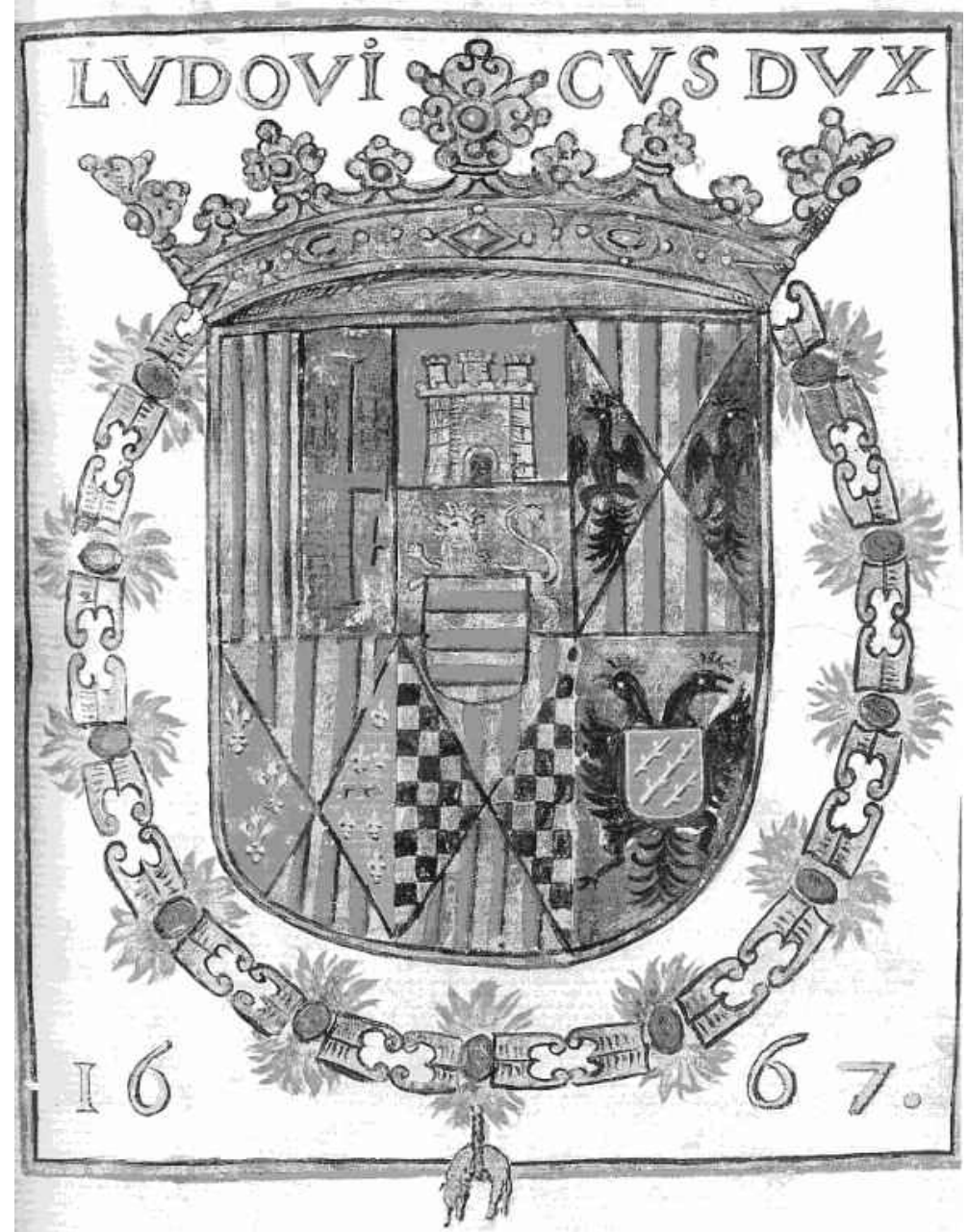

Fig. 10. Escudo de la casa de Segorbe-Cardona, en pergamino, de otro inventario de LLobet con las armas de Pallars en el último cuartel. 
b) A continuación se emplaza el inventario propiamente dicho, en el que la documentación queda agrupada en distintos bloques temáticos o series en correspondencia a la clasificación previa diseñada por Llobet de acuerdo con las directrices del noble propietario del Archivo.

De ese modo, la obra queda estructurada en tres partes diferenciadas, con el siguiente tratamiento temático:

- La primera parte sobre la descendencia, sucesión y «cosas domésticas» de los antiguos condes de Pallars.

- La segunda, sobre las «cosas comunes» al estado, lugares de jurisdicción civil, etc.

— La tercera parte sobre los «feudos» y rentas del marquesado.

Esta documentación quedaba así clasificada en distintos bloques temáticos o subfondos y series, donde sistematizaba y agrupaba Llobet -en grandes apartados y títulos capitulares - toda la documentación, lo que ayudaba a la memoria y comprensión total de la recopilación. En las introducciones a estos grandes epígrafes aprovecha el autor catalán para hacer auténticas narraciones históricas, hecho de relevante importancia por cuanto reafirma las razones de «prestigio» de la institución productora, inmersas en el sistema organizativo ideado por el archivero de Falset. Las regestas en muchos casos, y sobre todo en las series denominadas de «descendencia y sucesión», quedan introducidas a través de verdaderas relaciones históricas explicativas que ya hemos definido en otra parte como auténtica crónica señorial.

La ratio ordinis o distinción de este inventario llobetiano, así como de los restantes - hasta 10- que realizó en el Archivo de Segorbe-Cardona ${ }^{1}$, es por «armarios» y «cajones» (numerados en ambos casos por rigurosa disposición topográfica) hasta llegar a la «pieza documental» que, como ya dijimos, lleva un orden numérico correlativo a nivel general del fondo. La topografía responde a la clasificación previa, en las series cuyos títulos capitales abren los distintos apartados o capítulos del inventario, y también responde a la ordenación cronológica establecida que se concibe cerrada, pues muy raras veces se dejan espacios en blanco dentro del tomo manuscrito para futuras interpolaciones documentales.

La piezas, individuales o conjuntas, llevan como signatura, por tanto, el número que le corresponde, en caracteres arábigos. Así, para localizarlas, bastaba con mirar en los márgenes superiores del inventario, donde se reflejan los números de legajo y cajón a los que correspondían su instalación. Concretando aún más, la signatura completa de una pieza documental se componía del número de documento,

${ }^{1}$ En realidad, estos inventarios manuscritos del Archivo sobre los diversos estados o secciones documentales son ocho que, añadidos a las dos "Addiciones», hechas por Llobet a las recopilaciones de Busquets, hacen un total de diez inventarios. 
legajo, cajón y armario. Las escrituras sin fecha no suelen pasar al final de las series sino que se interpolan en consideración a la edad o tiempo aproximado que le correspondían.

El total de documentos inventariados y descritos por Llobet en 1662 de este histórico dominio pirenaico es de 1.617. Y la descripción interna o relación de contenido de las regestas de cada uno de esos documentos se pormenoriza así:

$1^{\circ}$.) El número correspondiente correlativo del documento, concordante con el que tenía dentro del fondo, a modo de encabezamiento.

$2^{\circ}$.) La regesta propiamente dicha o resumen del documento (extractos mucho más amplios que los que se reseñan al dorso de las escrituras), donde, en general, se recogen los siguientes datos:

- La tipología documental diplomática y jurídica.

- La referencia al organismo o persona productora (autor) y receptora (destinatario).

- El asunto o referencia argumental de la información (generalmente, muy adornado por Llobet).

- Algunos caracteres externos del documento, en ocasiones.

- Y la fecha o data, a renglón tendido del propio regesto, así como la especificación de la tradición documental sobre si el documento era original o copia y, en este caso, si era un traslado -mencionando el notario o escribano que lo autentificaba- o copia simple.

Los descriptores, por tanto, eran muy variados en extensión y generalmente bastante amplios.

El papel va pautado en tres márgenes, de los que sólo se utilizan el izquierdo (para anotar la signatura del cajón y legajo, e incluso en algún caso también el número del documento) y el central, que ocupa todo el eje o cuerpo del texto, donde se redactan esas amplias regestas. El margen lateral derecho queda en blanco y fue utilizado en algunos casos para reflejar addendas y correcciones o matizaciones a las propias relaciones de contenidos, con utilización de diversos signos gráficos que, a modo de llamadas, señalizan la zona del texto que corresponden a su lectura.

Para evitar desmembraciones, todos los folios del inventario quedan numerados por el anverso o recto, con 617 folios en un ejemplar y 671 en el otro.

c) Por último, concluye la Recopilación con índice topográfico o tabla alfabetizada de todas las villas, castillos y lugares de la jurisdicción del estado, con la indicación específica de las páginas donde están tratados, y con un índice general, 
con idéntica señalización de las páginas correspondientes, de cada epígrafe de la obra.

Llobet crea así por medio de este grueso volumen manuscrito un instrumento de descripción de los fondos pallarenses que tiene mucha importancia porque no se limita exclusivamente a hacer la simple regesta o resumen de contenido de cada documento del fondo sino que convierte su inventario en una auténtica crónica. El propio archivero se erige en historiador y, con la lógica salvedad que ofrece el hecho de saber en nuestros días que se trata de un cronista a sueldo del noble, su señor, limando los posibles partidismos y las lógicas alabanzas al señor, el inventario es una valiosa relación histórica de una utilidad extrema.

En sus páginas iniciales hay una gran cantidad de noticias sobre el Pallars, muy interesantes, dentro de una amplia introducción en la que se trata, entre otras muchas cosas, de la «antigüedad, nobleza, capacidad, límites, oficiales de justicia y modo de gobierno del Marquesado». Llobet contó para la realización de este trabajo con una ayuda fundamental: en 1628 un asesor del marqués, de nombre Onofre Timbau, que habitaba en Sort, escribió una completa relación sobre la situación del estado de Pallars en ese momento. Esa fuente la utiliza Llobet al hacer su inventario en 1662 y, uno y otro en sus manuscritos, dicen cosas como éstas acerca de este estado pirenaico:

"Tiene pues Vuestra Excelencia... a los fines de este Principado de Cataluña y a la parte del norte el sobredicho marquesado de Pallars que, como bien sabe, es una agregación de muchas villas, castillos y lugares, ...a saber: 9 villas, 75 lugares, 5 castillos, 1857 vecinos y más de 8.000 personas de comunión en 12 leguas de largo y 3 de ancho, con el cuerpo de las cuales está unido el título de marqués.

Los que le han regido y gobernado, en cuanto a la administración de la justicia y como a cabeza de él, han sido ordinariamente 2 gobernadores: el uno de los cuales ha residido en el castillo de la villa de Sort, con salario de 200 libras, el cual en dicho nombre rige y gobierna 5 villas, 53 lugares y 1140 vecinos, y ha tenido el mayor imperio, mando, señorío, jurisdicción para conocer, con parecer del asesor, de todos los negocios, pleitos y causas ansí civiles como criminales que adelante del dicho marquesado, ...el cual lleva una varilla pequeña y muy delgada en figura y demostración del mero y mixto imperio que por el serenísimo señor Rey Don Fernando fue concedido, juzgando en todo conforme las leyes proprias de este Principado, disposición de los sagrados cánones, leyes imperiales y consuetud(inarias) de la tierra; y el otro, con título de gobernador y castellán del valle de Àneu y castillo de Valencia, con salario de 120 libras y otros alimentos, el cual ha acostumbrado a administrar justicia más conforme a la consuetud de aquella valle que no conforme la disposición del derecho... 
Han tenido los predecesores de Vuestra Excelencia, y también Vuestra Excelencia, un asesor teórico y práctico en dicho marquesado, que conviene que lo sea porque assí, por la penuria de los abogados como por el poco dinero que hay, se llevan muy pocas causas en escripto, que casi todas las ha de decidir verbalmente; porque, a no ser teórico y práctico, fácilmente quitaría la hacienda a muchos sin conocerlo ellos, pues que los más de ellos dejan su justicia en la conciencia de él, por la cual razón y otras que por no ser prolijos se dejan, el tal asesor tiene summa necesidad de la gracia y temor de Dios, al cual ruego que se digne concederla a este indigno ministro suyo - se refiere al asesor Timbau, el autor de la relación susodicha-, que lo es por particular merced que V.E. le ha hecho para que no sea bastante ninguno de los poderosos enemigos del juez recto, como son amor, temor, ira y codicia, hacelle cometer cosa fea indigna de su oficio y de criado de Vuestra Excelencia, señalóme V.E. a los 7 de abril de 1622 en la villa de Arbeca por razón de mi oficio de asesor, el cual no sólo he ejercido pero la mayor parte del tiempo el de teniente de gobernador de dicha villa de Sort, cobrando 80 libras por mi salario con obligación de salir todas las veces que se ofreciere por el dicho marquesado y vizcondado de Villamur a alguna diligencia tocante a dicho mi oficio y a la buena administración de la justicia y de hacer todas las causas criminales sin pretender otra cosa, y aquellas consumo casi todas en el precio de alquiler de casa, que son 19 libras, y gasto de la mula que he tenido para acudir con más puntualidad a las cosas tocante a mi oficio y subidas de los castillos de Valencia y Tavascan por causa de los prisioneros que en las cárceles de aquellos castillos acostumbran a haber, y en los criados que llevo cuando voy de camino, y en otras cosas extraordinarias, por lo que para mayor descanso de mi vivienda me ayudo de tratos lícitos, decentes y agradables a Dios, a la ley y a la grey. Estas razones no he dicho - aclara Timbau a su señor no sé si con toda sinceridad-para animar a V.E. que me acreciente el salario porque, como el mayor interés es para mí estar bajo la sombra del árbol de V.E., no hago caso del interés pecuniario...

(Y sigue Llobet más adelante) ...También tiene V.E. otros oficiales en el cuerpo de dicho marquesado, como son el sobredicho tesorero, que por su salario se le tienen señaladas 40 libras para que se ocupe en mirar para el patrimonio de $V E$... Trata luego el archivero catalán de los salarios de los ministros de justicia y oficiales de guerra y de otros oficiales del Pallars indicando, por ejemplo, que el gobernador de la villa de Sort tiene un salario de 200 libras barcelonesas, el asesor 80 libras, el tesorero 40 libras; el gobernador además, aparte del salario y por su condición de castellán del castillo de València y por otros servicios que prestaba en el valle d’Àneu, tenía 12 quarteras de trigo, 40 de avena y otros emolumentos.

(A continuación el manuscrito llobetiano recoge un capítulo dedicado a la «Administración de la república del marquesado»), donde refiriéndose a los síndicos añade: ... En cuanto a la administración de dicho marquesado y república en común se ha de advertir que en él hay muchos administradores nombrados por los singulares de diferentes repúblicas, también comunes y particulares, que son y se llaman síndicos de los singulares de aquellas partes, hombres de idoneidad, legali- 
dad, virtud y buena fama, que se juntan en dicha villa de Sort cada cuando es menester, donde determinan las cosas convenientes a la buena administración de dicha república conforme les parece más a propósito por el bien común ...

(Más adelante Llobet, con ayuda de la Relación de Onofre Timbau, describe cada uno de los cuarteles territoriales en los que estaba dividido el marquesado de Pallars - con las poblaciones que los integran- y, por referirnos aquí sólo a uno de esos cuarteles, respecto al de Sort, dice situarse...) ...en un monte tan alto que parece que quiere competir con las mismas estrellas y predominar a todos los $\mathrm{Pi}$ rineos como en superioridad y altura los predomina, o por lo menos que, para gozar como goza de la hermosa vista de las santas peñas de Nuestra Señora de Montserrat, se ha empinado tanto...

(Y después, sobre esta población de Sort y su castillo, añade)

...La dicha villa de Sort está construida al pie del monte del que se hizo mención, a la parte de poniente de él y 4 leguas dentro de dichos montes Pirineos, en la cual hay 5 calles, más de 450 personas de comunión, 130 casas y sólo 49 de registro. Tiene un fuerte castillo habitación de los antiguos condes de Pallars, edificado a la parte del norte en un puesto rellenado y alto que domina y señorea toda la villa, el cual tiene dos puertas, una a la parte del oriente y otra entre la del norte y de poniente, la cual riega un suficiente arroyo de aguas cristalinas... Encierra dicho castillo dentro de sí un espacioso lugar (con) cuatro salas, una capilla y muchos aposentos que algún tiempo eran cual convenía a personas tales, los cuales el tiempo — consumidor de todo - ha gastado; una plaza enfrente de la puerta harto espaciosa, dos huertos aunque pequeños, seis torres grandes, las tres muy levantadas... la una de las cuales es a la parte casi del oriente, a la otra a la del norte y las otras a las de poniente, Ilamadas las torres cuadradas, las redondas y las de Casavall, y tres medias torres entre ellas y dos torreones fortísimos y muy levantados a la parte del oriente y de la villa, que verdaderamente no sólo dan gracia y hermosura al dicho castillo sino también a la villa; $y$ todo esto es dentro del circuito de él, fuera del muro cuya fortaleza y pertrechos de guerra que en él habían dan verdadera demostración y conocimiento de la antigüedad y nobleza de los condes predecesores de V.E.». 


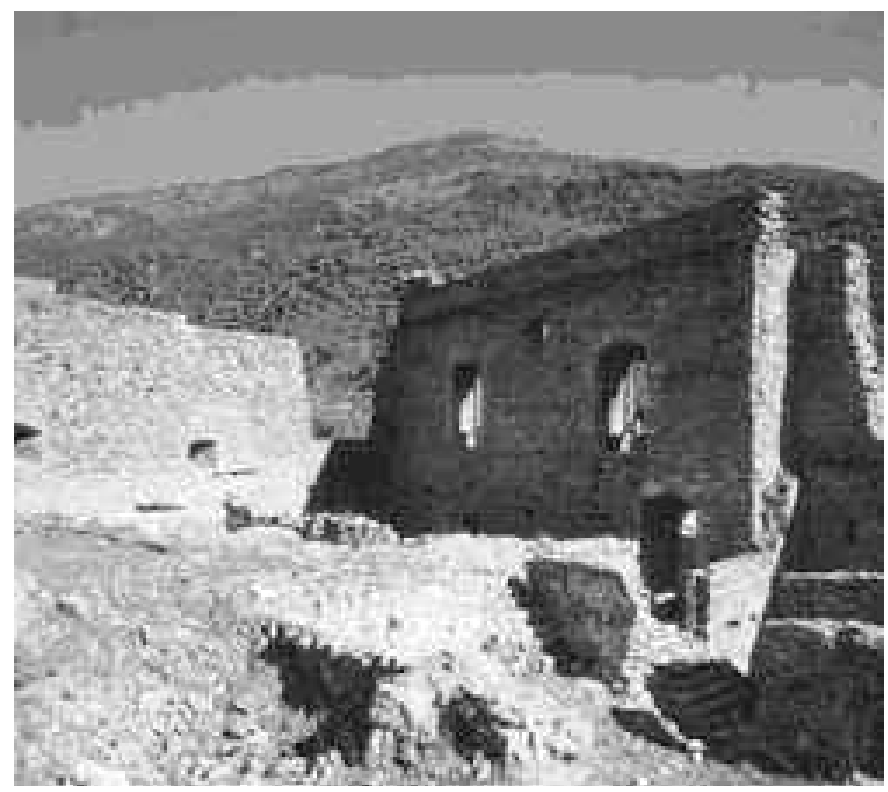

Fig. 11. Restos del castillo de Sort.

\section{BIBLIOGRAFÍA}

ABADAL i DE VINYALS, R. d': Catalunya Carolíngia. Barcelona, 1926-1955.

- Del visigots als catalans. Barcelona, 1962.

- Els primers comtes catalans. $2^{\mathrm{a}}$ edic. Barcelona. 1965.

- «Els preceptes comtals carolingis per al Pallars (segle IX)», en Boletín de la Real Academia de Buenas Letras de Barcelona. XXVI (Barcelona, 1954-1956.).

— «Pallars i Ribagorça en els segles IX i X», en Pirineos, vol. XIII, ns. 43-46 (Zaragoza, 1957).

- La formació de la Catalunya independent. Barcelona, 1970.

ALSINA DE LA TORRE, F.: «El último conde de Pallars. Documentos inéditos», en CHCA, IX (1973).

AVENTíN, M. y J. Ma SALRACH: «Del domini carolingi a la Independència», en Història de Catalunya coordinada por M. Riu, vol. 2. Barcelona, 1979.

BAUCELLS i REIG, J.: «La sucessió dels comtes de Pallars en el dos-cents», en Actas del X Congreso de Historia de la Corona de Aragón (Zaragoza, 1976), págs. 21-36.

BURILLO, X. y M. CAHNER: «Arbeca», en G.E.C., 2 (Barcelona, 1970), pág. 370.

CARRERAS i CANDI, F.: Geografía General de Catalunya. 6 vols. Barcelona (s.a.).

CASAS TORRES, J. M. y otros: España. Atlas e índices de sus términos municipales. Madrid, 1969. 2 tomos con anexo cartográfico.

FLUVIA i ESCORSA, A. de: «Los Condes y el Condado (después Marquesado) de Pallars», en Hidalguía, XXIV, nº 139 (Madrid, 1977), págs. 919-924.

- «Los vizcondes de Pallars, después llamados de Siarb, y finalmente de Vilamur», en Hidalguía, XXI, n ${ }^{\circ}$ 178-179 (Madrid, 1981), págs. 587-592.

GRAN GEOGRAFIA COMARCAL DE CATALUÑA, Vols. 1-12. Barcelona, 1975-1985.

HALPHEN, L.: Carlomagno y el Imperio Carolingio. México, 1955.

LLOBET, B. J.: Declaración del arbol de la genealogía y descendencia de los antiquíssimos, nobilíssimos y Excelentíssimos Vizcondes, Condes y Duques de Cardona en el Principado de Cataluña. Dirigida al Excelentíssimo y, por Real prerrogativa de la Real Sangre, Muy Ilustre Señor Don Luis-Ramon... Barcelona, 1665. 
LLOBET i MAS, F.: Cronología de los condes y marqueses de Pallars desde su erección hasta que sus estados pasaron a la Casa de Cardona, ms. 425 de la Biblioteca de Cataluña, fols. 1-110 vto.; colección diplomática de Guerra, ms. 426 de la misma Biblioteca.

MARTÍNEZ i TEIXIDO, L.: Las famílies nobles del Pallars en els segles XI i XII. Lleida: Pages, 1991.

MIRET i SANS, J.: «La princesa griega Láscaris, condesa de Pallars en Cataluña», en Revue Hispanique, X (1903), págs. 455-470.

OSTOS SALCEDO, P.: Génesis, tradición y formas del documento de los condes de Pallars (1288-1327) (Tesis doctoral s.p.) Universidad de Sevilla, 1985.

— «Roger de Comenge, Conde de Pallars, en el Archivo Ducal de Medinaceli (1229-1256)», en Espacio, Tiempo y Forma, Serie III, Ha Medieval, tomo 2 (1989), págs. 233-252.

PAZ Y MÉLIA, A.: Series de los más importantes documentos del Archivo y Biblioteca del Excmo. Sr. Duque de Medinaceli. 2 vols. Madrid, 1915 y 1924.

PELAEZ ALBENDEA, M. J.: Hugo Roger III, último conde de Pallars (1436-1503). (Tesis de licenciatura s.p.) Universidad de Barcelona, 1974.

- La actuación político-militar de Hugo Roger III de Pallars durante la guerra civil catalana del siglo XV. Barcelona, 1975.

— «Hugo Roger III, último conde de Pallars (1436-1503)», en Estudios de literatura, pensamiento, etc., pp. 341-400.

— «Pròleg» a Hug Roger III senyor de les muntanyes. Procés al darrer comte del Pallars. 1491, Pagès editors, Consell Cultural de les Valls d'Àneu, Lleida, 2002, pp. 13-16.

- «Hug Roger III durant la guerra civil de 1462-1472. El Capità General dels exèrcits de Catalunya i Conestable d'Aragó. Actuació política i militar», en Hug Roger III, darrer comte de Pallars. De la glòria a l'ocàs, Garsineu Edicions, Tremp. 2003, pp. 29-34.

PUIG i FERRETÉ, I. Ma: «Testaments comtals del Pallars Sobirà. La Casa de Comenge», en Urgellia, IV (1981), págs. 293-333.

- «La casa comtal de Pallars, senyora de Berga i de la baronia de Mataplana, als segles XIII i XIV», en Revista del Centre d'Estudis Beguedàns, 1 (Berga, 1982).

— «Els comtes de Pallars en els afers de Sicília. Anys 1281-1295»(1982).

— « La vall de Senyiu i els comtes de Pallars i Ribagorça» (1983).

RAVINA MARTÍN, M.: Documentación de Pallars en el Archivo Ducal de Medinaceli (974-1229). (Tesis de licenciatura s.p.) Universidad de Sevilla, 1972.

— «Documentos de Pallars en el Archivo Ducal de Medinaceli (Sevilla)», en Miscelánea de estudios dedicada al Prof. Antonio Marín Ocete. Tomo II (Granada, 1974), págs. 911-920.

RIBA i PALAU, A.: La fi del comtat de Pallars. Barcelona, 1923.

SALRACH, Josep $\mathrm{M}^{\mathrm{a}}$.: El procés de formació nacional de Catalunya (segles VIII-IX). 2 vols. Barcelona, 1972.

SÁNCHEZ GONZÁLEZ, A.: «Archivos Históricos: La Casa Ducal de Medinaceli», en Historia-16, n 75 (julio, 1982), págs. 117-122.

— «Los estados catalanes agregados a la Casa Ducal de Cardona», en Hidalguía, libro conmemorativo del XXV Aniversario de la Escuela de Genealogía, Heráldica y Nobiliaria. (Madrid, 1985), págs. 581-592.

— «Fondos documentales pirenaico-catalanes en el Archivo Ducal de Medinaceli», en Actas del VI Curs d'Estiu d'Estudis Pirinencs sobre «Arxiús i patrimoni documental al Pirineu», vol. III titulado Arxius al Pirineu (La Seu d’Urgell, 1987), págs. 8190.

— «El Archivo de los condes y marqueses de Pallars: génesis, evolución y organización documental», en revista Collegats I, Anuari del Centre d’Estudis del Pallars (Lérida, 1987), págs. 163-186.

- Documentación de la Casa Ducal de Medinaceli: El Archivo General de los Duques de Segorbe y Cardona. Madrid, 1990.

- «El Archivo General de la Casa Ducal de Medinaceli: un modelo de aportación de los Archivos Nobiliarios españoles a la ciencia Archivística», en Il futuro della memoria. Atti del Convegno Internazionale di studi sugli Archivi di famiglie e di persone, texto de la ponencia presentada en el Congreso Internacional de Archivos celebrado en Capri del 9 al 13 de septiembre de 1991 (dos volúmenes). Roma: Ministero per i Beni Culturali e Ambientali. Ufficio centrale per i Beni archivistici, 1997. Tomo I (págs. 347-367).

SÁNCHEZ i VILANOVA, L. El Comtat de Pallars Jussà (1011-1191). Lleida, 1989.

SANS i GENÉ, J. Mª y A. PAU i SANS: Arbeca, història i record. Arbeca, 1983.

SERRANO Y CABRERA, F.: Breve resumen de los derechos, regalías y rentas que el Excmo. Sr. Duque de Medinaceli, mi señor, goza en sus estados Ducado de Cardona y Marquesado de Aytona en este principado de Cataluña, con otras noticias que facilitan el mejor servicio a dichos estados. Barcelona, 1783. 
SOBREQUÉS VIDAL, S.: Els Barons de Catalunya. $4^{a}$ edic. Barcelona: Vicens Vives, 1991.

VALLS i TABERNER, F.: "Els origens dels comtats del Pallars i Ribagorça», en Estudis Universitaris Catalans, vol. X (Barcelona, 1915-1916).

- «La primera dinastía vescomtal de Cardona», en Estudis Universitaris Catalans, vol. XVI (Barcelona, 1923).

V.V.A.A.: Els castells catalans. 6 vols. $2^{a}$ edic. en castellano (dir. Pere CATALA i ROCA - edit. Rafael Dalmau). Barcelona, 1991. 